\title{
O DIÁLOGO ENTRE A ORGANIZAÇÃO DAS NAÇÕES UNIDAS E O BRASIL: A EDUCAÇÃO DAS PESSOAS COM DEFICIÊNCIA
}

\author{
Eneida Orbage de Britto Taquary ${ }^{1}$ \\ Catharina Orbage de Britto Taquary Berino ${ }^{2}$
}

RESUMO: Analisa os instrumentos internacionais da Organização das Nações Unidas sobre a educação das pessoas com deficiência e a sua recepção pelo Brasil. A metodologia será efetivada por intermédio da pesquisa bibliográfica. A problemática se refere à adoção de políticas de acesso e inclusão das pessoas com deficiência à educação em face dos tratados celebrados no âmbito do sistema global de proteção dos direitos humanos. O resultado se refere à adoção da Convenção de Nova York pelo Brasil denotando o diálogo entre o sistema global e o Brasil, a modificação da nossa legislação, inclusive com Emenda à Constituição Federal de 1988.

PALAVRAS-CHAVE: Educação Inclusiva; Pessoas com Deficiência; Organização das Nações Unidas - ONU; UNESCO; Brasil.

\section{THE DIALOGUE BETWEEN THE UNITED NATIONS ORGANIZATION AND BRAZIL: THE EDUCATION OF DISABLED PEOPLE}

\begin{abstract}
Analyzes the international instruments of the United Nations on the education of disabled people and their reception by Brazil. The methodology will be carried out through bibliographical research. The issue refers to the adoption of policies for access and inclusion of disabled people to education in view of the treaties celebrated within the scope of the global system for the protection of human rights. The result refers to the adoption of the New York Convention by Brazil denoting the dialogue between the global system and Brazil, the modification of legislation, including the Amendment to the Federal Constitution of 1988.
\end{abstract}

1 Advogada e sócia do Escritório de Advocacia Borges Taquary. É Delegada de Polícia Aposentada da Polícia Civil do Distrito Federal. Professora Doutora da Faculdade Presbiteriana Mackenzie BrasíliaDistrito Federal. Doutora em Direito pelo Centro Universitário de Brasília - UNICEUB, Mestre em Direito das Relações Internacionais pelo Centro Universitário de Brasília-UNICEUB e Mestre em Direito pela Universidade Católica de Brasília-UCB. Especialista em Segurança Pública, metodologia do ensino superior e Tribunais Superiores. Professora de Direito, com ênfase em Metodologia da pesquisa, Estudo da História do Direito, Direito Penal e Processual Penal, Legislação Penal e processual Penal Especial; Direito Internacional e Direitos humanos e humanitário. Autora dos livros: Crimes Contra os Costumes; Tribunal Penal Internacional e a Emenda Constitucional n ${ }^{\circ}$ 45/2004; Temas de Direito Penal e Direito Processual Penal; Proteção Internacional da Pessoa Humana: sistemas normativos de proteção; Mestre Thompson e outros mestres: edição em homenagem a Paulo Thompson Flores; Vida de Delegada I, Vida de Delegada II, Vida de Delegada III - Assédio e autora de diversos artigos científicos publicados. E-mail para contato: eneidataquary@yahoo.com.br

2 Advogada, Sócia do Escritório de Advocacia Borges Taquary, Professora Universitária (PhD em Direito), Escritora e Pesquisadora. É Pós Doutora e Doutora em Direito pelo Centro Universitário de Brasília - CEUB. É Mestre em Direito e Políticas Públicas pelo CEUB e pela Universidad del Litoral de Santa Fe - Argentina. É Especialista em Psicologia Jurídica, Direito Constitucional e Docência do Ensino Superior, Gestão e Tutoria EAD. É bacharel em Direito pelo CEUB. Dra. Catharina Taquary Berino é autora dos livros "A BoaFé no Direito Administrativo: A Legítima Expectativa como Limite à Burocracia", "O Direito Fundamental à Resolução Pacífica de Conflitos: Psicologia Jurídica, Mediação e Comunicação Não Violenta" e "Mediação no Século XXI: Tudo o Que Você Precisa Saber Sobre a Nova Forma de Resolver Conflitos". É Diretora do Centro de Pesquisa e Secretária da Comissão Nacional de Mediação da Associação Brasileira de Advogados - ABA. E-mail para contato: catharinaorbage@ yahoo.com.br

CONPEDI LAW REVIEW | EVENTO VIRTUAL | v. 7 | n. 2 | p. 20 - 38 | JUL - DEZ | 2021 
KEYWORDS: Inclusive Education; Disabled People; United Nations - UN; UNESCO; Brazil.

\section{INTRODUÇÃO}

O tema escolhido trata da necessidade de expansão das políticas públicas na educação das pessoas com deficiência, em especial com a formação e contratação de profissionais especializados, visando tornar pleno o direito à educação, que é previsto como direito humano no âmbito do sistema global e regional, bem como no rol de direitos fundamentais, na Constituição Federal (CF) de 1988.

Na Constituição Federal de 1988 está disposto no art. 6º com a natureza de direito social, e também está previsto no Título VIII, referente à Ordem Social, capítulo III, que trata da Educação, da Cultura e do Desporto. No art. 205, da CF, a educação é prevista como “direito de todos e dever do Estado e da família" e "será promovida e incentivada com a colaboração da sociedade, visando ao pleno desenvolvimento da pessoa, seu preparo para o exercício da cidadania e sua qualificação para o trabalho" (BRASIL. CONSTITUIÇÃO FEDERAL 1988).

O Brasil reconhece na Constituição Federal de 1988, no art. 206 que o ensino será ministrado com base nos seguintes princípios: I - igualdade de condições para o acesso e permanência na escola; II - liberdade de aprender, ensinar, pesquisar e divulgar o pensamento, a arte e o saber; III - pluralismo de ideias e de concepções pedagógicas, e coexistência de instituições públicas e privadas de ensino; IV - gratuidade do ensino público em estabelecimentos oficiais; V - valorização dos profissionais da educação escolar, garantidos, na forma da lei, planos de carreira, com ingresso exclusivamente por concurso público de provas e títulos, aos das redes públicas; VI - gestão democrática do ensino público, na forma da lei; VII - garantia de padrão de qualidade; VIII - piso salarial profissional nacional para os profissionais da educação escolar pública, nos termos de lei federal; IX - garantia do direito à educação e à aprendizagem ao longo da vida (BRASIL. CONSTITUIÇÃO FEDERAL 1988).

Os princípios acima expõem a desigualdade que existe na educação de pessoas com deficiência, quando se evidencia a falta de condições materiais e humanas, a começar pelo número de professores especializados contratados, e material inadequado para receber os alunos com as referenciadas deficiências. Essa desigualdade será analisada no decorrer do desenvolvimento do tema, bem como a dificuldade de se estabelecer ações afirmativas para 
estabelecer a igualdade material do acesso à educação, proporcionando condições para o acesso e permanência na escola, incentivando a pessoa no desenvolvimento do seu projeto de vida.

A problemática se refere à adoção de políticas de acesso e inclusão das pessoas com deficiência à educação em face dos tratados celebrados no âmbito do sistema global de proteção dos direitos humanos. Serão discutidos os documentos internacionais relativos ao direito de acesso à educação de pessoas com deficiência e sua permanência na escola, bem como a legislação nacional adotada em face da ratificação de referenciados tratados.

O objetivo geral é conhecer os instrumentos nacionais que disciplinam a educação como direito fundamental e os instrumentos internacionais que o consagram como direito humano; conhecer os mecanismos de inclusão, na educação, das pessoas com deficiência; e analisar os Tratados Internacionais elaborados no âmbito dos organismos da Organização das Nações Unidas sobre a educação das pessoas com deficiência e a sua recepção pelo Brasil.

A metodologia será efetivada por intermédio da bibliografia existente, em três etapas: em três etapas: a primeira que discute os tratados da organização das nações unidas sobre a educação de pessoas com deficiência e a legislação brasileira sobre o tema; a segunda que versa sobre a atuação da UNESCO e a terceira que versa sobre os mecanismos adotados nas instituições de ensino superior no Brasil para inclusão das pessoas com deficiência.

O resultado da análise realizada no artigo se refere à adoção dos Tratados sobre educação, pelo Brasil, assim como a modificação da nossa legislação, inclusive com Emenda à Constituição Federal de 1988.

\section{A EDUCAÇÃO COMO DIREITO HUMANO E FUNDAMENTAL}

Os direitos humanos são assim denominados porque previstos como direito de toda a humanidade, sem qualquer discriminação, e, portanto, previstos no Sistema Global ou Universal de Proteção de Direitos Humanos, estruturado na Organização das Nações UnidasONU, e seus órgãos.

Já a denominação de direito fundamental à educação é utilizada porque inserta na Constituição da República Federativa do Brasil de 1988, no seu art. $6^{\circ}$, referente aos Direitos Sociais, e ainda nos seus arts. 206 e seguintes, dispondo como direito de todos e dever do Estado e da família. Portanto, a denominação de direitos fundamentais é caracterizada pela garantia do direito à educação e à aprendizagem ao longo da vida. 
A educação como direito humano está disciplinada no sistema global de proteção dos direitos humanos, que tem como espinha dorsal a Declaração Universal de Direitos Humanos e nos seus Pactos de Direitos Civis, Políticos, Econômicos e Culturais. O sistema global é também chamado de sistema onusiano, porque criado quando do surgimento da Organização das Nações Unidas -ONU e em sua estrutura, em substituição à Sociedade das Nações, por força da eclosão da Segunda Guerra Mundial.

\section{SISTEMA GLOBAL DE DIREITOS HUMANOS}

A espinha dorsal de todo o sistema internacional de direitos humanos, segundo Cançado Trindade (1997), advém da Declaração Universal dos Direitos Humanos, de 1948, que foi adotada por todos os Estados-membros da ONU, e que se completou na década de 60 com os Pactos Internacionais de Direitos Econômicos, Sociais e Culturais e de Direitos Civis e Políticos, constituindo o sistema normativo global geral de proteção dos direitos humanos, denominado de sistema onusiano (ONU. 2021).

A Declaração Universal dos Direitos Humanos surgiu como proposta do Conselho Econômico e Social e foi aprovada pela Resolução da III Seção Ordinária da Assembleia Geral das Nações Unidas, caracterizando-se pela transcendência sobre quaisquer regimes políticos ou jurídicos, tendo autoridade reconhecida e efetiva como "fonte de legitimidade para toda ação legisladora e inquisitiva que efetue a Comunidade Internacional em matéria de direitos humanos" (PIOVESAN. 2012).

A Carta da Organização das Nações Unidas - ONU constitui o primeiro ato internacional e logo a primeira fonte do Direito Internacional da qual irradiam muitas outras, em razão de sua estrutura (ONU. 2021).

As obrigações impostas pela Carta da ONU têm supremacia sobre qualquer outro tratado celebrado entre Estados membros da ONU, tendo força cogente, consoante o art. 103, do Capítulo XVI, das disposições gerais (ONU. 2021).

Os atos praticados pela ONU denotam a sua capacidade jurídica necessária para o exercício das suas funções e a realização e seus propósitos, no território de cada um de seus membros, conforme art. 104 (ONU. 2021). Sua personalidade jurídica se realiza no âmbito internacional com sua atuação independentemente dos Estados-membros e no interno com a organização de seu funcionamento e coordenação entre os seus órgãos (ONU. 2021). 


\section{O DIÁLOGO ENTRE A ORGANIZAÇÃO DAS NAÇÕES UNIDAS E O BRASIL: \\ A EDUCAÇÃO DAS PESSOAS COM DEFICIÊNCIA}

A ONU, por intermédio de seus órgãos é composto pela Assembleia Geral, o Conselho de Segurança, a Corte Internacional de Justiça, o Conselho de Tutela, o Secretariado e o Conselho Econômico e Social (ONU. 2021).

Estes são os estatutários. Os órgãos subsidiários podem ser criados, mas vinculados às necessidades dos órgãos estatutários. É interessante notar, que cada órgão estatutário da ONU produz atos necessários ao desenvolvimento de suas funções. Esses atos produzem efeitos na esfera internacional, no momento em que visando a segurança internacional e relações amistosas entre as nações com fundamento, nos princípios da igualdade de direito, autodeterminação dos povos e fortalecimento da paz universal. (ONU. 2021)

A Assembleia Geral da ONU (AGNU.2021) é composta por todos os 193 Estadosmembros, que os admite por decisão e mediante recomendação do Conselho de Segurança. É órgão representativo, normativo e deliberativo. Suas decisões são tomadas por maioria de dois terços quando se tratam de ameaça à paz e segurança mundiais, admissão de novos membros e assuntos correlatos, os demais assuntos são decididos por maioria simples.

A AGNU como órgão central da ONU ao lado do Conselho de Segurança, constituem os pilares da Organização. O primeiro é responsável pelas discussões acerca da "manutenção da paz e da segurança internacionais, que a ela forem submetidas por qualquer Membro das Nações Unidas, ou pelo Conselho de Segurança, ou por um Estado que não seja Membro das Nações unidas" (art. 35, $\S 2^{\circ}$ ). Também faz recomendações ao Estado-membro ou Estados interessados, ou ao Conselho de Segurança ou a ambos sobre a manutenção da paz e segurança internacionais. Todavia, as ações necessárias devem ser submetidas ao Conselho de Segurança pela Assembleia Geral, antes ou depois da discussão (ONU. art.11.2.2021).

A AGNU também faz recomendações com o objetivo de estabelecer o alcance das imunidades dos membros e funcionários da ONU no território dos Estados membros (ONU. Art.105. 2020). O art. 10 da Carta da ONU atribui a AGNU o poder de fazer recomendações sobre assuntos e questões dos Estados-membros e do Conselho de Segurança. As recomendações da $\mathrm{AG}$ forma durante muitas décadas consideradas como recomendações não vinculantes, não gerando obrigatoriedade para os Estados-Membros, ou denominadas de soft law.

As recomendações da AGNU são geradas no âmbito de discussões de todos os Estados-membros, que acabam por gerar uma obrigatoriedade de conduta, com natureza de comandos normativos, por expressar valores comuns que são apreciados, discutidos e 
aprovados pela sociedade internacional, sendo indiscutivelmente fonte do direito internacional, resultando em declarações e celebração de tratados.

O Conselho de Segurança (CS) tem sua estrutura definida no art. 23 da Carta da ONU. Composto por quinze membros, mas cinco permanentes, com direito a veto, e dez membros não permanentes, eleitos por dois anos, sem direito a reeleição, com vistas a manutenção da paz e da segurança internacional e para os outros propósitos da Organização e também a distribuição geográfica equitativa.

As funções do CS estão disciplinadas na Carta da ONU. São elas: manter a paz e a segurança internacional (art. 24); investigar toda e qualquer situação que possa eclodir conflito internacional (art. 39/40); determinar a criação, continuação e encerramento das Missões de Paz, de acordo com os Capítulos VI, VII e VIII da Carta (art. 33 e segs.); recomendar métodos de diálogo entre os países (art. 36); elaborar planos de regulamentação de armamentos (art. 26); determinar se existe uma ameaça para a paz (art.39); solicitar aos países que apliquem sanções econômicas e outras medidas para impedir ou deter alguma agressão (art. 41); recomendar o ingresso de novos membros na ONU (art. 18); recomendar para a Assembleia Geral a eleição de um novo Secretário-Geral (art.97) (BRASIL. NAÇÕES UNIDAS.2021).

Nas suas funções de determinar se existe uma ameaça para a paz e solicitar aos países que apliquem sanções econômicas e outras medidas para impedir ou deter alguma agressão fica evidente o impedimento do Estado-membro de alegar o domínio reservado para não se submeter as recomendações do CS, regra prevista no art. 25: “[...] os membros das Nações Unidas concordam em aceitar e executar as decisões do Conselho de Segurança, de acordo com a presente Carta [...]” (BRASIL. NAÇÕES UNIDAS.2021).

As recomendações do CS, diversamente do que se entende das recomendações da AGNU, tem caráter cogente, possuindo natureza jurídica de normas, logo de caráter obrigatório para todos os Estados-membros, vinculando-os, denominando-as de hard law.

A Corte Internacional de Justiça é o órgão jurisdicional do sistema global ou sistema onusiano, exercendo funções jurisdicionais e consultivas, consoante os arts. 92 e segs. da Carta da ONU. Suas decisões judiciais vinculam os Estados-membros da ONU, que sejam partes no conflito, sendo obrigatório o cumprimento da decisão, sob pena de ficar sujeito às recomendações do CS (art. 94). Os Estados não membros da ONU poderão figurar na CIJ, em razão de recomendação da AGNU ou do CS, excepcionalmente. A CIJ em sua competência consultiva poderá emitir opiniões que tenham sido provocadas pela AGNU, CS, órgãos da 
ONU e seus organismos especializados, no interesse de suas competências e atividades (art. 96, CARTA DA ONU).

O Conselho Econômico e Social (ECOSOC) é o órgão coordenador do trabalho econômico, social e ambiental da ONU, das Agências Especializadas e das demais instituições integrantes do Sistema das Nações Unidas. É órgão responsável pelo acompanhamento das conferências e cúpulas da ONU e pela coordenação de uma série de comissões econômicas e sociais técnicas, regionais, programas e fundos, agências especializadas, institutos visando o “desenvolvimento sustentável, fornecendo orientação e coordenação geral”, com vistas no desenvolvimento da vida das pessoas, promovendo o respeito aos direitos humanos e as liberdades fundamentais.

Congrega parcerias em todo o mundo com organizações governamentais e não governamentais registradas, com fim de reformular políticas públicas. Todos os anos, o órgão estabelece um tema para estruturar seu trabalho que contribua para o desenvolvimento sustentável, incluindo o Fórum Político de Alto Nível e o Fórum de Cooperação para o Desenvolvimento orientando e fazendo recomendações para o desenvolvimento sustentável e o cumprimento dos compromissos assumidos, bem como a cooperação par ao desenvolvimento.

O ECOSOC congrega além da Organização Mundial da Saúde, a FAO (Organização das Nações Unidas para a Alimentação e a Agricultura); a OIT (Organização Internacional do Trabalho); a UNESCO (Organização das Nações Unidas para a Educação, Ciência e Cultura) e o Conselho de Direitos Humanos, além de muitas outras organizações, sendo responsável pelas declarações de Direitos Humanos; Direitos dos Povos Indígenas; Tratado de Roma e Orientação sexual e identidade de gênero.

A UNESCO é a organização das Nações Unidas para a Educação, a Ciência e a Cultura e será objeto de nossa análise no tocante aos órgãos da ECOSOC, porque criada para desenvolver, monitorar e promover normas e padrões de educação, com o objetivo de "promover a implementação do direito à educação em nível de país e avançar os objetivos da Educação" (UNESCO. 2021).

A Organização das Nações Unidas para a Educação, a Ciência e a Cultura (UNESCO) é uma agência especializada das Nações Unidas (ONU) com sede em Paris, fundada em 4 de novembro de 1946. Tem por objetivo construir a paz, erradicar a pobreza e impulsionar o desenvolvimento sustentável. Atua nas áreas de Educação, Ciências Naturais, Ciências Humanas e Sociais, Cultura e Comunicação e Informação, desenvolvendo projetos de 
cooperação técnica e projetos com Estados-membros, mas também com a sociedade civil e a iniciativa privada(BRASIL. MEC.2021).

$\mathrm{Na}$ área da educação, a UNESCO fornece "liderança global e regional em educação, fortalece os sistemas de educação em todo o mundo e responde aos desafios globais contemporâneos por meio da educação tendo a igualdade de gênero como um princípio subjacente" (UNESCO.2021).

A atuação da organização abrange o desenvolvimento educacional da pré-escola ao ensino superior e além. Os temas incluem cidadania global e desenvolvimento sustentável, direitos humanos e igualdade de gênero, saúde e HIV e AIDS, bem como desenvolvimento de habilidades técnicas e vocacionais", sendo a única agência da ONU com mandato para promover todos os aspectos a educação, inclusive a Agenda de Educação Global 2030 por meio da Meta de Desenvolvimento Sustentável 4 - ODS-4, que tem como metas: educação primária e secundária universal; desenvolvimento da primeira infância e educação préprimária universal; igualdade de acesso ao ensino técnico/profissional e superior; habilidades relevantes para um trabalho decente; igualdade e inclusão de gênero; alfabetização universal de jovens; educação para o desenvolvimento sustentável e cidadania global (UNESCO. 2021).

A Representação da UNESCO no Brasil está situada em Brasília e foi inaugurada em 1964, mas passou a funcionar em 1972, em parceria com o Ministério da Educação-MEC. O MEC com a UNESCO objetiva a "promoção de ações com vistas ao desenvolvimento de uma educação de qualidade - assegurar a educação inclusiva, equitativa e de qualidade e promover oportunidades de aprendizagem ao longo da vida para todas e todos, conforme previsto no Objetivo de Desenvolvimento Sustentável no 4 (ODS-4)" (BRASIL. MEC.2021).

Para viabilizar a ODS-4, a UNESCO conta com a Convenção contra a Discriminação na Educação, que disciplina vários aspectos do direito à educação (objetivos, metas e ferramentas) tendo força obrigatória no direito internacional, caracterizando hard law.

A Convenção contra a Discriminação na Educação estabelece que a educação deve objetivar o desenvolvimento pleno da pessoa humana e o fortalecimento do respeito pelos direitos humanos e pelas liberdades fundamentais; a liberdade dos pais de escolher a educação dos filhos, de acordo com suas convicções morais e religiosas e ainda o direito dos membros de minorias nacionais de exercerem suas próprias atividades educacionais (UNESCO. 2020).

$\mathrm{O}$ instrumento reafirma o "princípio de que não devem ser estabelecidas discriminações e proclama o direito de todos à educação" (UNESCO.2020) e as 
“discriminações na esfera do ensino constituem uma violação de direitos enunciados na Declaração Universal de Direitos Humanos”(UNESCO. 2020).

Os Estados Partes no referenciado documento devem implementar o direito à educação, gratuita e obrigatória, em relação ao ensino primário que equivale ao ensino fundamental, bem como o acesso disponível e acessível a todos ao ensino médio; equivalência dos padrões educacionais em todas as instituições de ensino públicas do mesmo nível e com as mesmas condições em termos de qualidade; oportunidades de treinamento para aqueles que perderam toda ou parte de sua educação primária e educação posterior e oportunidades de treinamento para a profissão docente, sem discriminação (UNESCO. 2020).

\section{A PROTEÇÃO DAS PESSOAS COM DEFICIÊNCIA}

$\mathrm{Na}$ esfera internacional, apesar do sistema global ou onusiano ter sido completado com os Pactos Internacionais de Direitos Civis e Políticos e de Direitos Econômicos, Sociais e Culturais - ECOSOC, de 1966, muitas outras convenções foram aprovadas, mas em defesa dos direitos da pessoa com deficiência somente em 1971, por intermédio da resolução $\mathrm{n}^{\circ}$. 2856 da Assembleia Geral da ONU, quando foi promulgada a Declaração dos Direitos das Pessoas com Retardos Mentais (ONU.AG. RESOLUÇÃO 26/ 2856).

A Declaração reafirmava a discriminação das pessoas com retardos mentais, ao estabelecer que os direitos seriam conferidos as pessoas com deficiência mental, na medida do possível, aos que forem conferidos aos demais seres humanos, estabelecendo uma distinção e distanciamento no trato legal entre pessoas com deficiências mentais (ONU.AG. RESOLUÇÃO 26/ 2856).

No ano de 1975, a resolução n ${ }^{\circ}$ 3447/ONU, foi instituída a Declaração dos Direitos das Pessoas com Deficiência, definindo como sendo a pessoa incapaz de satisfazer por si própria, no todo ou em parte, as necessidades de uma vida normal individual e/ou social, em resultado de deficiência, congénita ou não, nas suas faculdades físicas ou mentais, não estabelecendo diferenciação entre as pessoas com deficiência e as demais pessoas em direitos e dignidade (ONU.AG. RESOLUÇÃO 30/3447).

A ONU nos anos de 1981 e 1982 instituiu o Ano Internacional das Pessoas com Deficiência, "com o objetivo de trazer atenção à causa, promover participação plena" e a “igualdade das pessoas com deficiência" (ONU.AG. RESOLUÇÃO 37/52), assim como a "prevenção de deficiências, a reabilitação, a acessibilidade das pessoas com deficiência e a CONPEDI LAW REVIEW | EVENTO VIRTUAL | v. 7 | n. 2 | p. 20 - 38 | JUL - DEZ | 2021 
busca por romper com barreiras atitudinais". (ANDRADE.2013) e o Programa de Ação Mundial para as Pessoas com Deficiência, adotado pela Assembleia Geral através da resolução $n^{\circ}$. 37/52, buscando a interação da pessoa com deficiência ao seu ambiente social ao indivíduo (ONU. AG).

Em 1983 a Organização Internacional do Trabalho-OIT foi editada a Convenção sobre Reabilitação Profissional e Emprego de Pessoas com Deficiência ( ${ }^{\circ}$. 159), visando a participação e a igualdade das pessoas com deficiência, de forma material e não apenas formal(ONU.OIT.2021).

As resoluções $n^{\circ}$ 45/91 e 48/93 da Assembleia Geral da ONU estabeleceram, respectivamente, a execução do Programa de Ação Mundial para as Pessoas com Deficiência, visando a operacionalização do programa e as Normas para Equiparação de Oportunidades para Pessoas com Deficiência (ONU. AG). Posteriormente a ONU produziu os seguintes documentos:

A - 1996, data da 24. ${ }^{a}$ Declaração Universal dos Direitos Linguísticos, promovida pela UNESCO em Barcelona, que destacou: “ todas as comunidades linguísticas têm direito a decidir qual deve ser o grau de presença da sua língua, como língua veicular e como objeto de estudo, em todos os níveis de ensino no interior do seu território: pré-escolar, primário, secundário, técnico e profissional, universitário e formação de adultos” (UNESCO. 2021);

B - 1999, data da Convenção da Guatemala, que aprovou a Convenção Interamericana para a Eliminação de Todas as Formas de Discriminação contra as Pessoas Portadoras de Deficiência e ainda, em Londres, elaborada a Carta para o Terceiro Milênio da Reabilitação Internacional, pela Assembleia Geral de Reabilitação Internacional;

C - 2002, Congresso Europeu de Pessoas com Deficiência, através do qual ficou estabelecido o ano de 2003 como o Ano Europeu das Pessoas com Deficiência, realizado em Madri;

D - 2003, Primeiro Congresso Europeu Sobre Vida Independente, realizado em Tenerife; 2004, proclamado o Ano das Pessoas com deficiência e o Dia Internacional das Pessoas com Deficiência, 03 de dezembro;

E - E finalmente no ano de 2007, a Convenção de Nova York, que prestigiou a inclusão das pessoas com deficiência, destacando a acessibilidade, a educação, acesso à justiça e principalmente o conceito de pessoa com deficiência, nos moldes da $24^{a}$ Declaração Universal dos Direitos Linguísticos, que prevê que " todas as línguas são a expressão de uma identidade coletiva e de uma maneira distinta de apreender e descrever a realidade, pelo que 
devem poder beneficiar das condições necessárias ao seu desenvolvimento em todas as funções" (UNESCO.2021).

A adoção da Convenção de nova York e seu Protocolo facultativo decorreu da resolução GA A / RES / 61/106, adotada pela Assembleia Geral das Nações Unidas em 13 de dezembro de 2006 e que foi aberto para assinaturas em 30 de março de 2007 e entrou em vigor em 3 de maio de 2008 após a ratificação pelo $20^{\circ}$ Estado Parte. O tratado foi ratificado pela União Europeia e também pelo Brasil. Possui 147 signatários (ONU.2020).

A Convenção adota "uma ampla categorização das pessoas com deficiência e reafirma que todas as pessoas com todos os tipos de deficiência devem gozar de todos os direitos humanos e liberdades fundamentais" (ONU. 2020).

No âmbito da Convenção mencionada, são classificados e qualificadas "todas as categorias de direitos se aplicam às pessoas com deficiência e identifica as áreas onde a adaptação deve ser feita para que as pessoas com deficiência exerçam efetivamente seus direitos e as áreas onde seus direitos foram violados e onde a proteção dos direitos deve ser reforçada" (ONU. 2020).

No Brasil, a Convenção de Nova York foi a primeira Convenção a ser aprovada na forma do art. $5, \S 3^{\circ}$, que determina que terão força de emendas à Constituição, os "tratados e convenções internacionais sobre direitos humanos que forem aprovados, em cada Casa do Congresso Nacional, em dois turnos, por três quintos dos votos dos respectivos membros", dispositivo introduzido pela EC No 45/2004. Logo, seu texto ingressou na Constituição Federal de 1988 e modificou a infraconstitucional, em especial a legislação civil e penal, quanto à capacidade das pessoas com deficiência e ainda determinou a edição de farta legislação sobre a acessibilidade à educação e amplo atendimento às pessoas surdas ou com deficiência auditiva (ONU.2021).

A Convenção de Nova York estabelece no seu art. 24, o direito das pessoas com deficiência à educação, sem que haja discriminação e com base na igualdade de oportunidades. Para alcançar este objetivo deverá ser assegurado um sistema educacional inclusivo em todos os níveis e também um aprendizado ao longo de toda a vida (ONU.2021).

O direito das pessoas com deficiência à educação deve ser pautado pelos seguintes objetivos: a. o pleno desenvolvimento do potencial humano e do senso de dignidade e autoestima, além do fortalecimento do respeito pelos direitos humanos, pelas liberdades fundamentais e pela diversidade humana; b. o desenvolvimento máximo possível personalidade e dos talentos e criatividade das pessoas com deficiência, assim de suas 
habilidades físicas e intelectuais; c. a participação efetiva das pessoas com deficiência em uma sociedade livre (ONU.2021).

A deficiência não pode ser motivação para a exclusão do sistema educacional geral, destacando-se as crianças, do sistema do ensino fundamental gratuito e compulsório, de qualidade e gratuito, nas mesmas condições com as demais pessoas na comunidade em que vivem, recebendo o apoio necessário no âmbito do sistema educacional geral, com vistas a facilitar sua efetiva educação e o desenvolvimento acadêmico e social, compatível com a meta de inclusão plena (ONU. 2021).

A promoção da identidade linguística da comunidade surda também está prevista no instrumento intencional acima mencionado, com a facilitação do aprendizado da língua de sinais e o aprendizado do braile, escrita alternativa, modos, meios e formatos de comunicação aumentativa e alternativa, e habilidades de orientação e mobilidade, além de facilitação do apoio e aconselhamento de pares, para garantir a educação de pessoas, inclusive crianças cegas, surdo-cegas e surdas.

A capacitação de professores e profissionais inclusive professores com deficiência, habilitados para o ensino da língua de sinais e/ou do braile, para atuar em todos os níveis, ensino fundamental, médio e superior. A referenciada Convenção e seu protocolo facultativo trouxe alterações na legislação mundial, em especial no Brasil, que a adotou na forma de Emenda à Constituição.

\section{DIREITO À EDUCAÇÃO COMO DIREITO FUNDAMENTAL}

No Brasil, a Convenção de Nova York e seu protocolo facultativo foi promulgada em 25 de agosto de 2009, por intermédio do Decreto $n^{\circ}$ 6.949, após aprovação legislativa datada de 09 de julho de 2008, pelo Decreto Legislativo no 186.

Dentre a legislação mencionada, a Lei $\mathrm{n}^{\mathrm{o}}$ 10.098, de 19 de dezembro de 2000 estabeleceu as normas e critérios básicos para a promoção da acessibilidade das pessoas portadoras de deficiência ou com mobilidade reduzida, estabelecendo no art. $2^{\circ}$, III, que pessoa com deficiência é "aquela que tem impedimento de longo prazo de natureza física, mental, intelectual ou sensorial, o qual, em interação com uma ou mais barreiras, pode obstruir sua participação plena e efetiva na sociedade em igualdade de condições com as demais pessoas" e ainda no inciso IX, a definição de comunicação como "forma de interação dos cidadãos que abrange, entre outras opções, as línguas, inclusive a Língua Brasileira de 


\section{O DIÁLOGO ENTRE A ORGANIZAÇÃO DAS NAÇÕES UNIDAS E O BRASIL: \\ A EDUCAÇÃO DAS PESSOAS COM DEFICIÊNCIA}

Sinais (Libras), a visualização de textos, o Braille, o sistema de sinalização ou de comunicação tátil, os caracteres ampliados, os dispositivos multimídia” (BRASIL. 2021).

A Lei $n^{\circ} 10.436$, de 24 de abril de 2002 estabeleceu no seu art. $1^{\circ}$ e seu parágrafo único, o reconhecimento da Língua Brasileira de Sinais - Libras e outros recursos de expressão a ela associados como meio legal de comunicação e expressão das comunidades de pessoas surdas do Brasil, constituindo "um sistema linguístico de natureza visual-motora, com estrutura gramatical própria, de transmissão de ideias e fatos" (BRASIL. 2021), e ainda no art. $4^{\circ}$, a responsabilidade do Estado, nas esferas municipais, estaduais, federal e também o Distrito Federal, “de garantir a inclusão nos cursos de formação de Educação Especial, de Fonoaudiologia e de Magistério, em seus níveis médio e superior, do ensino da Língua Brasileira de Sinais - Libras, como parte integrante dos Parâmetros Curriculares Nacionais PCNs, conforme legislação vigente" (BRASIL. 2021).

O dispositivo acima citado ainda estabelece a equiparação à "linguagem simples, escrita e oral, os sistemas auditivos e os meios de voz digitalizados e os modos, meios e formatos aumentativos e alternativos de comunicação, incluindo as tecnologias da informação e das comunicações" (BRASIL. 2021).

O Decreto $n^{\circ} 5.626$, de 22 de dezembro de 2005 regulamentou as leis acima (Lei $n^{\circ}$ 10.436, de 24 de abril de 2002, e o art. 18 da Lei $\mathrm{n}^{\circ}$ 10.098, de 19 de dezembro de 2000, ao definir no art. $2^{\circ}$, que a pessoa surda é "aquela que, por ter perda auditiva, compreende e interage com o mundo por meio de experiências visuais, manifestando sua cultura principalmente pelo uso da Língua Brasileira de Sinais - Libras" e a deficiência auditiva é a " perda bilateral, parcial ou total, de quarenta e um decibéis (dB) ou mais, aferida por audiograma nas frequências de $500 \mathrm{~Hz}, 1.000 \mathrm{~Hz}, 2.000 \mathrm{~Hz}$ e $3.000 \mathrm{~Hz}$ ".

O referenciado Decreto inseriu no seu art. $3^{\circ}$, a disciplina Libras como obrigatória no curso de "formação de professores para o exercício do magistério, em nível médio e superior, e nos cursos de Fonoaudiologia, de instituições de ensino, públicas e privadas, do sistema federal de ensino e dos sistemas de ensino dos Estados, do Distrito Federal e dos Municípios", e como disciplina optativa nos demais cursos de educação superior e na educação profissional (BRASIL. DECRETO N 5.626. 2021).

Ainda previu, no art. $4^{\circ}$, a formação de docentes de pessoas surdas e também para o ensino de Libras nas séries finais do ensino fundamental, no ensino médio e na educação superior deve ser realizada em nível superior, em curso de graduação de licenciatura plena em Letras: Libras ou em Letras: Libras/Língua Portuguesa como segunda língua, e na educação 
infantil e nos anos iniciais do ensino fundamental no curso de Pedagogia ou curso normal superior, em que Libras e Língua Portuguesa escrita tenham constituído línguas de instrução, viabilizando a formação bilíngue (BRASIL. DECRETO Nº 5.626. 2021).

O instrutor de Libras, em nível médio, é formado por meio dos cursos de educação profissional; cursos de formação continuada promovidos por instituições de ensino superior; e cursos de formação continuada promovidos por instituições credenciadas por secretarias de educação, mas poderá ser realizada também por organizações da sociedade civil representativa da comunidade surda, desde que o certificado seja convalidado por pelo menos uma das instituições acima referidas (BRASIL. DECRETO No 5.626. 2021).

Por intermédio da Lei 12.319 , de $1^{\circ}$ de setembro de 2010, a profissão de Tradutor e Intérprete da Língua Brasileira de Sinais - LIBRAS foi regulamentada, atribuindo competência para "realizar interpretação das 2 (duas) línguas de maneira simultânea ou consecutiva e proficiência em tradução e interpretação da Libras e da Língua Portuguesa", estabelecendo ainda, no art. $6^{\circ}$, as atribuições do tradutor e intérprete, tal qual a de "efetuar comunicação entre surdos e ouvintes, surdos e surdos, surdos e surdos-cegos, surdos-cegos e ouvintes, por meio da Libras para a língua oral e vice-versa”, em atividades didáticopedagógicas e culturais em todos os níveis, atuando nos processos seletivos para cursos na instituição de ensino e nos concursos públicos e no apoio ao acesso aos serviços e atividades- fim das instituições de ensino e órgãos públicos, bem como em auxiliar em serviços realizados junto ao órgãos judiciais, policiais e administrativos (BRASIL.2021).

No ano de 2014, a Lei 13.055, de 22 de dezembro instituiu o Institui o Dia Nacional da Língua Brasileira de Sinais - LIBRAS e dispôs sobre sua comemoração no dia 24 de abril de cada ano.

A legislação evoluiu para o Estatuto da Pessoa com Deficiência ou Lei Brasileira de Inclusão da Pessoa com Deficiência, a Lei no 13.146, de 06 de julho de 2015, "destinada a assegurar e a promover, em condições de igualdade, o exercício dos direitos e das liberdades fundamentais por pessoa com deficiência, visando à sua inclusão social e cidadania”, (BRASIL. 2021) baseada na Convenção sobre os Direitos das Pessoas com Deficiência e seu Protocolo Facultativo, ratificados pelo Congresso Nacional por meio do Decreto Legislativo $\mathrm{n}^{\mathrm{o}} 186$, de 9 de julho de 2008, e promulgados pelo 2009, data de início de sua vigência no plano interno.

A lei acima mencionada, tal qual a Convenção de Nova York, previu, um capítulo exclusivo, tratando do direito à educação das pessoas com deficiência reconhecendo 
expressamente esse direito e assegurando um sistema educacional inclusivo em todos os “ níveis e aprendizado ao longo de toda a vida, de forma a alcançar o máximo desenvolvimento possível de seus talentos e habilidades físicas, sensoriais, intelectuais e sociais, segundo suas características, interesses e necessidades de aprendizagem.” (BRASIL.Art.27.2021).

A educação de qualidade ofertada à pessoa com deficiência é dever do Estado, da família, da comunidade escolar e da sociedade, realizando ações para promoção e tutela das pessoas com deficiência, de forma a colocá-la "a salvo de toda forma de violência, negligência e discriminação" (BRASIL.2021).

O sistema educacional brasileiro deve ser inclusivo em todos os níveis e modalidades, visando a garantir condições de acesso, permanência, participação e aprendizagem, por meio da oferta de serviços e de recursos de acessibilidade que eliminem as barreiras e promovam a inclusão plena (BRASIL.2021).

A legislação brasileira em consonância com a Convenção de Nova York prevê o sistema educacional inclusivo em todos os níveis e modalidades, bem como o aprendizado ao longo de toda a vida, garantir o projeto pedagógico que "institucionalize o atendimento educacional especializado, assim como os demais serviços e adaptações razoáveis, para atender às características dos estudantes com deficiência e garantir o seu pleno acesso ao currículo em condições de igualdade, promovendo a conquista e o exercício de sua autonomia.” (BRASIL.2021).

Também dispõe sobre a educação bilíngue em Libras como primeira língua e na modalidade escrita da língua portuguesa como segunda língua, em escolas e classes bilíngues e em escolas inclusivas e formação e disponibilização de professores para o atendimento educacional especializado, de tradutores e intérpretes da Libras, de guias intérpretes e de profissionais de apoio.

No Brasil, segundo dados do Instituto Nacional de Estudos e Pesquisas Educacionais Anísio Teixeira (Inep), no ano de 2020, foram registradas 47,3 milhões de matrículas nas 179,5 mil escolas de educação básica no Brasil, cerca de 579 mil matrículas a menos em comparação com 2019, o que corresponde a uma redução de 1,2\% no total, sendo majoritariamente na área urbana $(89,1 \%)$.

Nas redes pública e privada rede privada, 99\% das matrículas estão em escolas urbanas e na rede pública, as escolas municipais são as que apresentam a maior proporção de 
matrículas na área rural, com 18,5\%, seguidas das escolas federais, com 12,6\% (BRASIL.INEP.2021).

No ensino médio, foram registradas 7,6 milhões de matrículas em 2020, aumentando $1,1 \%$ no último ano. Esse crescimento interrompe a tendência de queda observada nos últimos anos (redução de 8,2\% de 2016 a 2019) (BRASIL.INEP. 2021).

O número de matrículas da educação de jovens e adultos (EJA) segue em tendência de queda, reduzindo 8,3\% no último ano e chegando a 3,0 milhões em 2020 e o número de matrículas da educação profissional apresentou crescimento nos últimos três anos. Em relação ao último ano, o número de matrículas aumentou 1,1\%(BRASIL.INEP. 2021).

O número de matrículas da educação especial chegou a 1,3 milhão em 2020 , um aumento de $34,7 \%$ em relação a 2016. O percentual de matrículas de discentes incluídos em classe comum também vem aumentando gradativamente, passando de 89,5\%, em 2016, para 93,3\%, em 2020, dentre os alunos entre 4 e 17 anos (BRASIL.INEP. 2021).

Por fim, na educação superior, o número de matrículas em cursos de graduação presencial diminuiu 3,8\% entre 2018 e 2019. No modelo de educação à distância, o aumento é de $19,1 \%$ no mesmo período, mais que o crescimento registrado no período 2017/2018 (17,0\%). Ainda no período de 2018 e 2019, o número de concluintes na rede pública apresentou uma queda de $-3,1 \%$; na rede privada a variação negativa é de $0,6 \%$. No período de 2009 a 2019, a variação percentual do número de concluintes em cursos de graduação é maior na rede privada, com $32,7 \%$; enquanto na pública esse crescimento é de $21,5 \%$ no mesmo período.

\section{CONCLUSÃO}

A adoção da Convenção de Nova York e seu Protocolo facultativo, decorrente da Resolução GA A / RES / 61/106) é um Tratado de Direitos Humanos adotados pela Assembleia Geral das Nações Unidas em 13 de dezembro de 2006 e que foi aberto para assinaturas em 30 de março de 2007 e entrou em vigor em 3 de maio de 2008 após a ratificação pelo $20^{\circ}$ Estado Parte.

O instrumento internacional decorrente do sistema global dialoga com a legislação brasileira. Sua aprovação e incorporação legislativa, na forma do art. $5^{\circ}, \S 3^{\circ}$, que ingressou como Emenda Constitucional por ter sido aprovada "em cada Casa do Congresso Nacional, 
em dois turnos, por três quintos dos votos dos respectivos membros", dispositivo introduzido pela EC No 45/2004.

A ratificação da Convenção de Nova York pelo Brasil e por muitos países, 182 atualmente, denota a integração do sistema global com os sistemas regionais de proteção dos direitos humanos e também com o sistema nacional brasileiro, garantindo o direito das pessoas com deficiência à educação, sem que haja discriminação e com base na igualdade de oportunidades, assegurado um sistema educacional inclusivo em todos os níveis e também um aprendizado ao longo de toda a vida.

\section{REFERÊNCIAS}

ANDRADE, Wagner Teobaldo Lopes de. Variação fonológica da LIBRAS: um estudo sociolinguístico de comunidades surdas da Paraíba. 2013. Disponível em: https://repositorio.ufpb.br/jspui/bitstream/tede/6416/1/arquivototal.pdf. Acesso: 17/07/2021.

BRASIL. Censo da Educação Básica 2020: Notas Estatísticas. Instituto Nacional de Estudos e Pesquisas Educacionais Anísio Teixeira. Brasília, DF: INEP, 2021.

BRASIL. Lei $\mathbf{n}^{0} \mathbf{1 0 . 0 9 8}$, de 19 de dezembro de 2000. Estabelece normas gerais e critérios básicos para a promoção da acessibilidade das pessoas portadoras de deficiência ou com mobilidade reduzida, e dá outras providências. Diário Oficial da República Federativa do Brasil, Brasília, DF, 20 dez. 2000. Seção 1 - Eletrônico, p. 2 (Publicação Original). Disponível em: http://www.planalto.gov.br/ccivil_03/leis/110098.htm. Acesso em: 17/07/2021.

BRASIL. Lei $\mathrm{n}^{\circ}$ 10.436, de 24 de abril de 2002. Dispõe sobre a Língua Brasileira de Sinais - Libras e dá outras providências. Diário Oficial da República Federativa do Brasil, Brasília, DF, 25 abr. 2002. Seção 1 - p. 23 (Publicação Original). Disponível em: http://www.planalto.gov.br/ccivil_03/leis/2002/110436.htm. Acesso em: 16/07/2021.

BRASIL. Decreto $n^{0}$ 5.626, de 22 de dezembro de 2005. Regulamenta a Lei $n^{0} \mathbf{1 0 . 4 3 6}$, de 24 de abril de 2002, que dispõem sobre a Língua Brasileira de Sinais - Libras, e o art. 18 da lei 10.098, de 19 de dezembro de 2000. Diário Oficial da República Federativa do Brasil, Brasília, DF, 23 dez. 2005. Seção 1, p. 28 (Publicação Original). Disponível em: http://www.planalto.gov.br/CCIVIL_03/_ato2004- 2006/2005/decreto/d5626.htm. Acesso em: 17/07/2021.

BRASIL. Lei $\mathbf{n}^{\circ}$ 12.319, de $1^{\circ}$ de setembro de 2010. Regulamenta a profissão de Tradutor e Intérprete da Língua Brasileira de Sinais. Diário Oficial da República Federativa do Brasil, Brasília, DF, 2 set. 2010. Seção Extra, p.1. Disponível em: http://www.planalto.gov.br/ccivil_03/_ato2007-2010/2010/lei/112319.htm. Acesso em: 17/07/2021. 
BRASIL. Lei $\mathrm{n}^{\circ}$ 13.146, de 6 de julho de 2015. Institui a Lei Brasileira de Inclusão da Pessoa com Deficiência (Estatuto da Pessoa com Deficiência). Diário Oficial da República Federativa do Brasil, Brasília, DF, 7 jul. 2015. Seção 1. p. 2. Disponível em: http://www.planalto.gov.br/ccivil_03/_ato2015-2018/2015/lei/113146.htm. Acesso em: 17/07/2021.

BRASIL. NAÇÕES UNIDAS. Conselho De Segurança. Disponível em: https://nacoesunidas.org/conheca/como-funciona/conselho-de-

seguranca/\#: :text=O \%20Conselho\%20de\%20Seguran\%C3\%A7a\%20\%C3\%A9,Assembleia $\%$ 20Geral\%20por \%20dois\%20anos. Acesso em: 20/08/2021.

LIMA, Cristiane Helena de Paula. O Caráter Obrigatório das Decisões do Conselho de Segurança Das Nações Unidas. Disponível em http://centrodireitointernacional.com.br/static/revistaeletronica/volume4/arquivos_pdf/ sumario/art_v4_XV.pdf. Acesso em 20/08/2021.

ORGANIZAÇÃO DAS NAÇÕES UNIDAS (ONU). CARTA DA ONU. Disponível em https://www.un.org/es/charter-united-nations/index.html. Acesso em 02/08/2021

ORGANIZAÇÃO DAS NAÇÕES UNIDAS. RESOLUÇÃO DA ASSEMBLEIA GERAL DA ONU no 377 , de 3 de novembro de 1950. Disponível em https://unispal.un.org/DPA/DPR/unispal.nsf/0/55C2B84DA9E0052B05256554005726C6.

Acesso em 02/08/2020.

ORGANIZAÇÃO DAS NAÇÕES UNIDAS. RESOLUÇÃO DA ASSEMBLEIA GERAL DA ONU no 2856, de 20 de setembro de 1971. Disponível em https://undocs.org/es/A/RES/2856(XXVI). Acesso em 02/08/202.

ORGANIZAÇÃO DAS NAÇÕES UNIDAS. RESOLUÇÃO DA ASSEMBLEIA GERAL DA ONU $\mathbf{n}^{\circ}$ 3447, de 09 de dezembro de 1975. Disponível em https://undocs.org/es/A/RES/3447(XXX). Acesso em 02/08/2021

ORGANIZAÇÃO DAS NAÇÕES UNIDAS. RESOLUÇÃO DA ASSEMBLEIA GERAL DA ONU no 37/52, de 03 de dezembro de 1982. Disponível em https:// https://undocs.org/es/A/RES/37/52. Acesso em 02/08/2021.

ORGANIZAÇÃO INTERNACIONAL DO TRABALHO. Resolução da Assembleia da República n. ${ }^{\circ}$ 63/98 Convenção n. 159 da Organização Internacional do Trabalho, respeitante à readaptação profissional e ao emprego de deficientes. Disponível em https://abres.org.br/wp-content/uploads/2019/11/convencao_n_159_sobre_reabilitacao_profis sional_e_emprego_de_pessoas_deficientes_deoit_1_6_1983.pdf. Acesso em 02/08/2021.

PIOVESAN, Flávia. Direitos Humanos e o Direito Constitucional Internacional. 13. ed. São Paulo: Saraiva, 2012. p. 225-242.

TRINDADE, Antônio Augusto Cançado. Dilemas e desafios da Proteção Internacional dos Direitos Humanos no limiar do Século XXI. Rev. bras. Polít. int., Brasília, v. 40, n. 1, p. 167- 177, June 1997. Disponível em: . Acesso em: 20/08/2020. 
UNESCO. Building Peace In The Minds Of Men And Women. Disponível em: https://web.archive.org/web/20110510060808/http://www.unesco.org/new/en/unesco/. Acesso em: 28/08/2021.

UNESCO. Declaração Universal Dos Direitos Linguísticos (1996). Declaração De Barcelona. Disponível em: http://www.penclubeportugues.org/comites/declaracao-universaldos-direitos-linguisticos/. Acesso em: 28/08/2021. 